\title{
Phase behavior of UCST blends: Effects of pristine nanoclay as an effective or ineffective compatibilizer
}

\author{
F. Hemmati ${ }^{1}, H$. Garmabi $^{1 *}, H$. Modarress $^{2}$ \\ ${ }^{1}$ Department of Polymer Engineering and Color Technology, Amirkabir University of Technology, No. 424, Hafez Ave., \\ Tehran, Iran \\ ${ }^{2}$ Department of Chemical Engineering, Amirkabir University of Technology, No. 424, Hafez Ave., Tehran, Iran
}

Received 2 June 2013; accepted in revised form 18 August 2013

\begin{abstract}
The effects of unmodified nanoclay (natural montmorillonite) on the miscibility, phase behavior and phase separation kinetics of polyethylene (PE)/ethylene vinyl acetate copolymer (EVA) blends have been investigated. Depending on the blend composition, it was observed that the intercalated pristine nanoclay influences the biphasic morphology either as an effective compatibilizer or just as an ineffectual modifier. In spite of the presence of micrometer-sized agglomerated tactoids, natural nanoclay can play a thermodynamic role in reducing the interfacial tension of polymer components. The addition of clay nanoparticles was found to change the phase diagram slightly and diminishes the composition dependency of the binodal temperatures. Moreover, it was observed that a small amount of unmodified layered silicate slows down the phase separation process considerably and enhances the solubility of each polymer in the domains of its counterpart. The findings of this study verify that even poorly dispersed nanoclay with high surface tension can act as a conventional compatibilizer and change the immiscible PE/EVA blends to the partially miscible ones.
\end{abstract}

Keywords: polymer blends and alloys, miscibility, nanocomposites, rheology, phase separation

\section{Introduction}

Blending of polymers is a well-established route to create new materials, which have ultimate properties of the components to offer in a single product. However, most of polymer pairs result in immiscible blends having biphasic morphology that affects all final characteristics. One of the classical strategies to enhance the miscibility of two phases is the addition of a third component as compatibilizer. This strategy not only provides an opportunity to modify the microstructure, but also gives a chance to improve the final properties of the blends [1]. A newly developed concept, presented in this area, is the use of inorganic nanofiller in a binary blend to enhance the compatibility of polymeric components. It has been found that the addition of solid nanoparticles with at least one dimension in the nanometer scale can affect the compatibility of components and improve the physical, mechanical and thermal properties of the blends [2-5]. The improved miscibility of polymer mixtures in the presence of nanofillers has been reported by different groups with reduced dispersed phase domains, narrower droplet size distribution in matrix-dispersed morphology, enhanced ductility and mechanical properties, lower interfacial tension between two phases and more morphological stability in the subsequent melt blending processes [5-10]. As shown theoretically by Nesterov and Lipatov [11-12], the compatibilization effect of solid filler $(F)$ on an immiscible polymer pair $(A$ and $B)$ can be described by the mixing free energy of system $\left(\Delta G_{\text {mix }}\right)$ which consists of the absorption free energy of each polymer on the solid surface of $F\left(\Delta G_{\mathrm{AF}}\right.$ and $\left.\Delta G_{\mathrm{BF}}\right)$ and the interaction

${ }^{*}$ Corresponding author, e-mail: garmabi@aut.ac.ir BME-PT 
energy between two polymeric components $\left(\Delta G_{\mathrm{AB}}\right)$ as expressed by Equation (1):

$$
\begin{aligned}
\Delta G_{\mathrm{mix}} & =\Delta G_{\mathrm{AF}}+\Delta G_{\mathrm{BF}}+\Delta G_{\mathrm{AB}} \\
& =R T\left(\chi_{\mathrm{AF}} \varphi_{\mathrm{A}} \varphi_{\mathrm{F}}+\chi_{\mathrm{BF}} \varphi_{\mathrm{B}} \varphi_{\mathrm{F}}+\chi_{\mathrm{AB}} \varphi_{\mathrm{A}} \varphi_{\mathrm{B}}\right)
\end{aligned}
$$

where $\varphi_{\mathrm{i}}$ is the volume fraction of $i^{\text {th }}$ component and $\chi_{\mathrm{ij}}$ is the Flory-Huggins interaction parameter between components $i$ and $j$. As the authors stated, the binary blend containing solid filler would be more miscible in the case of the absorption of either both polymers or one of them preferentially on the surface of filler (either $\Delta G_{\mathrm{AF}}$ and $\Delta G_{\mathrm{AF}}<0$ or one of them become less than zero). In addition to the mentioned enthalpic gain, the absorption of polymer chains on the filler surface is accompanied by another impact, that is the entropic reduction of the polymer chains, named 'entropic surface tension' of nanoparticles [13]. According to the simulation work of Balazs et al. [14], preferential wetting of nanofiller by one of the polymers results in slower kinetics of spinodal decomposition. Therefore, nanoparticle addition to binary mixtures and preferential absorption of polymer chains could slow down the domain growth and cause a pinning influence on the interface motions. In the similar manner, it was experimentally observed that the addition of nanoparticles could diminish the diffusion of absorbed polymeric chains and retard the phase separation phenomena $[15,16]$. As it is found by Lipatov et al. [11, 12], this 'non-equilibrium' compatibilization mechanism of nanofillers is more profound at higher concentrations of the inorganic component wherein the distance of two adjacent solid particles in the system can be comparable to the gyration radius of unperturbed polymer coils. Contrary to the non-equilibrium compatibilization mechanism, the equilibrium mechanism is accompanied by a promoted thermodynamic stability of the hybrid system. Zhang et al. [17] studied the thermodynamic effect of nanoclay in an immiscible polymer blend as an equilibrium phenomenon whereupon the biphasic morphology was stabilized during the annealing time. The applied time scale of experiments was much longer than the time scale required for polymer diffusion. By incorporation of other inorganic nano-size particles including spherical fillers and nanotubes in the blend, this was observed that nanoclay with large aspect ratio is more efficient in compatibilizing and reducing the interfacial tension by providing large amounts of in-situ grafts between two components at the interface.

Although there have been several researches on different aspects of nanofiller induced miscibility in the binary blends, the phase diagram and the interaction parameter of polymeric pairs in the presence of inorganic nanoparticles have not been studied intensively. The effect of fumed silica on the phase diagram of a lower critical solution temperature (LCST) blend was investigated $[11,12]$ and it was found that the miscibility window of phase diagram directly impressed depending on the filler concentration. The thermodynamic implications were proposed to govern by simultaneous action of two mechanisms: selective absorption of one of polymers on the solid surface and redistribution of macromolecules with respect to their molecular weights between the bulk and the boundary layer (in the vicinity of filler surface) and the alteration of the interaction parameter between polymer constituents. Likewise, Yurekli et al. [18] studied the effects of layered silicate on the phase behavior of polystyrene (PS)/poly(vinyl methyl ether) (PVME) blends. They observed that the phase transition boundary was not considerably changed by adding 0.04 volume fraction of nanoclay. In contrast to their work, Huang et al. [19] found that the addition of nanosilica increased the phase separation temperature of a LCST blend and diminished the interaction parameter $\left(\chi_{\mathrm{AB}}\right)$. Moreover, the solubility of each component in the other phase domains was enhanced. Following by them, Mabrouk et al. [20, 21] reported that nanoclay could alter the phase behavior both by thermodynamics and kinetics effects and the phase transition mechanism changes from spinodal decomposition to nucleation and growth by addition of nanoparticles. Using the same binary blends, Gharachorlou and Goharpey [22] by means of rheology examined the influence of hydrophilic nanosilica having the size comparable to the chain gyration radius and illustrated the phase boundary increased up to $10^{\circ} \mathrm{C}$ toward the heterogeneous region, despite the fact that nanoparticles migrated to one of the component domains. Interestingly, Gao et al. [23] stated that the compatibilizing effect of nano-size silica on the phase separation temperature of the studied LCST blends strongly depended on the blend composition. Also, they deduced that micron size silica could scarcely make 
a noticeable impact on the phase separation of blend.

As explained, different aspects of nano-size particle compatibilization influence on varied binary blends have been addressed in the literature. Among them, the phase behavior alteration of LCST blends in the presence of inorganic nanofillers is worth mentioning. However, to the best of our knowledge, the implications of nanoparticles for phase behavior of the upper critical solution temperature (UCST) blends needs to be investigated. In this work, in order to study the influences of inorganic nanofiller on the miscibility window and phase separation kinetics of an UCST blend, polyethylene (PE)/ethylenevinyl acetate copolymer (EVA) blends were chosen and compounded with natural montmorillonite (MMT) clay. The phase transitions of these blends including liquid-liquid and solid-liquid phase separation had been evaluated previously. It is noteworthy that PE/EVA/clay hybrid systems with enhanced thermal properties and flame retardancy are demanded for wire and cable insulating applications extensively [4]. The main objective of the present research is to examine the effects of unmodified nanoclay on the miscibility of PE/EVA blends during phase transition phenomenon. Attempts are particularly made to answer this question that whether or not the nanoparticles can act as an effective interfacial modifier while the enthalpic interactions of polymer-filler pairs are extremely weaker than the enthalpic interaction of two polymer components; i.e. $\chi_{\mathrm{AF}}$ and $\chi_{\mathrm{BF}}>>\chi_{\mathrm{AB}}$. Because of this goal, pristine nanoclay without any surface modification was chosen as nanofiller. Moreover, another concern of the present study is to probe the nanoclay localization influences on the biphasic microstructure and composition-dependent interactions existed in the PE/EVA blends. By means of linear viscoelastic responses, effort is made to track the effects of chain confinement on the kinetics of phase separation phenomena. In addition to the rheological measurements, dynamic mechanical analysis (DMA), microscopic observations and interfacial tension measurements were carried out to support the findings of this work.

\section{Experimental part}

\subsection{Materials and sample preparation}

High density polyethylene (HDPE, BL3 grade) from Arak Petrochemical Company (Arak, Iran) and ethylene vinyl acetate copolymer (EVA, Seetec VA910) from Hyundai Company (Seoul, South Korea) and natural montmorillonite (MMT, Cloisite $\mathrm{Na}^{+}$) from Southern Clay Products Inc. (Texas, USA) were used as received. The characteristics of the polymeric components are presented in Table 1. Irganox B225 (Ciba Specialty Chemicals Inc., Basel, Switzerland) was applied to thermally stabilize the prepared samples at $0.1 \mathrm{wt} \%$. PE/EVA blends and PE/ EVA/MMT compounds at various polymer concentrations, ranging from 30 to $70 \%$ of EVA by weight, were prepared by a laboratory batch internal mixer (BRABENDER PL2200, Duisburg, Germany) at a temperature of $155^{\circ} \mathrm{C}$ with a rotor speed of $60 \mathrm{rpm}$. Melt-compounding was continued for $10 \mathrm{~min}$ then the film and sheet samples were prepared by compression molding at temperature of $150^{\circ} \mathrm{C}$ under $15 \mathrm{MPa}$ pressure. The concentration level of MMT was fixed at $3 \mathrm{wt} \%$. In the remaining parts, the samples will be coded as PExEVAyMMTz wherein $x, y$ and $z$ stand for PE, EVA and MMT weight fractions, respectively. For samples in which one of the components is not included, the material's name will be omitted from the corresponding code.

\subsection{Characterization}

\subsubsection{Rheological measurements}

All the rheological measurements were performed using a parallel plate Paar-Physica rheometer (diameter of $25 \mathrm{~mm}$, gap of $1 \mathrm{~mm}$, Ashland, VA 23005, USA). To prevent moisture absorption and sample degradation, all examinations were carried out at nitrogen atmosphere. The performed small amplitude oscillatory shear measurements consisted of:

Table 1. Characteristics of the studied materials

\begin{tabular}{|c|c|c|c|c|c|c|}
\hline Sample & $\begin{array}{l}\text { Density } \\
{\left[\mathrm{g} / \mathrm{cm}^{3}\right]^{\mathrm{a}}}\end{array}$ & $\begin{array}{c}\text { MFI } \\
{[\mathrm{g} / 10 \mathrm{~min}]^{\mathrm{a}}}\end{array}$ & $\begin{array}{c}\text { VAc content } \\
{[w t \%]^{\mathrm{a}}}\end{array}$ & $\begin{array}{c}\mathbf{M}_{\mathrm{w}} \\
{[\mathrm{g} / \mathrm{mol}]^{b}}\end{array}$ & $\begin{array}{c}\text { PDI }^{\mathbf{b}} \\
\left(\mathbf{M}_{w} / \mathbf{M}_{n}\right)\end{array}$ & $\begin{array}{c}\text { OIT } \\
{\text { [min }]^{\mathrm{c}}}^{\text {Ond }}\end{array}$ \\
\hline HDPE & 0.954 & 1 & - & 330000 & 6.2 & $>200$ \\
\hline EVA & 0.950 & 400 & 28 & 56000 & 3.6 & $>90$ \\
\hline
\end{tabular}

agiven by the supplier

${ }^{b}$ measured using PL-GPC 220 High Temperature GPC/SEC System (Agilent Technologies, California, USA)

${ }^{\mathrm{c}}$ measured at $180^{\circ} \mathrm{C}$ in pure oxygen atmosphere using the stabilized samples 
(a) Isochronal dynamic temperature ramps by reducing the temperature from the mixed region $\left(180^{\circ} \mathrm{C}\right)$ to the phase-separated region, at a small strain in the linear viscoelastic regime $(1 \%$, as determined by preliminary isothermal dynamic strain sweeps) and the cooling rate of $1^{\circ} \mathrm{C} / \mathrm{min}$; (b) Isothermal dynamic time sweep for $3 \mathrm{hr}$ at temperatures in the vicinity of phase separation boundary at a fixed frequency of $1 \mathrm{~s}^{-1}$ and a given strain of $1 \%$, in order to evaluate the phase separation kinetics. Seeking this purpose, the samples were annealed at $180^{\circ} \mathrm{C}$, and then quenched to the desired temperature to track the rate of phase separation. In addition, dynamic time sweeps at $180^{\circ} \mathrm{C}$ for $50 \mathrm{~min}$ were performed on the stabilized PE, EVA, PE100MMT3 and EVA100MMT3 samples to ensure that the measurements were carried out without the interference of thermal degradation. Apart from the mentioned rheological examinations, the oxidation induction time (OIT) measurements demonstrated that the oxidation reaction of the mentioned samples began at times longer than $90 \mathrm{~min}$ in pure oxygen atmosphere; (c) Isothermal dynamic frequency sweeps at a linear strain of $1 \%$ were also performed.

\subsubsection{Morphological observations}

Demixing temperature of the prepared samples were determined by optical microscopy (Leica DMRX, Buffalo Grove, IL 60089, USA) equipped with a heating block (Linkam LTS 350, Surrey, UK) using films having the thicknesses about $50 \mu \mathrm{m}$. The cooling rate inside the heating block was $1{ }^{\circ} \mathrm{C} / \mathrm{min}$. To investigate the state of nanoclay dispersion and localization, the height and phase mode images of the atomic force microscopy (AFM) were prepared using a Dualscope, DME Atomic Force Microscope (Copenhagen, Denmark) equipped with a DS 95-50-E scanner and an AC probe. Biphasic morphology of samples was examined using a field emission scanning electron microscopy (Hitachi High-Technologies Co., Tokyo, Japan). The cryofractured samples were etched in xylene (Extra pure, Ph Helv vl, Merck KGaA, Darmstadt, Germany) for $6 \mathrm{hr}$ at $50^{\circ} \mathrm{C}$ to extract the EVA-rich domains selectively. The droplet size for the samples with matrix-dispersed morphology was measured using image analysis software. The average diameter of dispersed domains $\left(D_{\mathrm{v}}\right)$ was calculated from the area of the domains in SEM micrographs.
At least 250 dispersed-phase domains were analyzed for each sample. To determine the EVA continuity index and to study the biphasic morphology in 3 dimensions, the samples with the specified weights were stirred in xylene for 7 days at a constant temperature of $50^{\circ} \mathrm{C}$ for selectively removal of EVA domains. The weight fraction of the extracted EVA phase was determined as the co-continuity index of EVA-rich phase. For probing the nanoclay dispersion more precisely, TEM micrographs were prepared using a Philips CM-30 (Amsterdam, Netherlands) operating at accelerating voltage of $200 \mathrm{kV}$. Following the same approach, XRD patterns were recorded on a Philips XPERT diffractometer (Almelo, The Netherlands) using $\mathrm{Cu}$ tube. Data were obtained within the scattering angles of $1-10^{\circ}$ at a step size of $0.02^{\circ}$.

\subsubsection{Thermal analysis}

To study the miscibility of the polymeric component in the amorphous region, the viscoelastic properties of the sheet samples were measured by DMA using TTDMA Dynamic Mechanical Analyzer (Triton Technology Ltd, Lincolnshire, UK). The experiments were performed in single bending mode from -160 to $100^{\circ} \mathrm{C}$ at a frequency of $1 \mathrm{~Hz}$ with a programmed heating rate of $5^{\circ} \mathrm{C} / \mathrm{min}$.

\subsubsection{Interfacial tension measurement}

Interfacial tension of PE/EVA in the pure state and in the presence of nanoclay was measured using sessile drop and imbedded fiber retraction methods at temperature of $155^{\circ} \mathrm{C}$. For sessile drop measurements, the drops of EVA were formed on the sheets of PE and PE100MMT3. The samples were remained in nitrogen atmosphere until the mechanical equilibrium was reached (approximately $5 \mathrm{hrs}$ ). Then, the samples were suddenly cooled down to $0^{\circ} \mathrm{C}$, fixed, cut with a surgical blade, and then observed using optical microscope. Afterwards, the contact angles were measured. The interfacial tensions were evaluated by the Neumann triangle rule using the surface tensions of PE, EVA and PE100MMT3 samples at $155^{\circ} \mathrm{C}$. The surface tensions were determined using a pendant drop instrument at nitrogen atmosphere and the results are collected in Table 2. Another method used to measure the interfacial tension in this study was imbedded fiber retraction. The melt spun threads of PE and PE100MMT3 were chopped and annealed at temperature of 
$100^{\circ} \mathrm{C}$ for $24 \mathrm{hr}$ in a vacuum oven, then, the short fibers were imbedded in a matrix of pure EVA. Moreover, the PE short fiber sandwiched between two EVA100MMT3 films was also prepared. The obtained sandwich type assemblies were placed in the heating block of optical microscopy and heated to $155^{\circ} \mathrm{C}$. Then, the evolution of the fibers was recorded. Using Carriere and Cohen's theory [24, 25], the interfacial tension between fibers and matrices were measured. The zero shear viscosity of the samples required for the calculations were determined by the isothermal dynamic frequency sweeps using Carreau-Yasuda model [26] and the obtained data are presented in Table 2. The results of interfacial tension measurements given in the following sections are the arithmetic means of 3-5 replicates. To ensure that the examinations were carried out in stable conditions without the interference of thermal degradation, themogravimetry analysis (TGA) were performed using a Shimadzu TGA-50 Thermoanalyzer instrument (Kyoto, Japan) in nitrogen atmosphere. The obtained results indicated that the weight loss of PE, EVA, PE100MMT3 and EVA100MMT3 samples were negligible for $5 \mathrm{hr}$ at temperature of $155^{\circ} \mathrm{C}$.

The interfacial tension of EVA/MMT and PE/MMT were determined via contact angle measurement of the polymer melt drops on nanoclay disks. The MMT powder were pressed into hard disks under $15 \mathrm{MPa}$ pressure. The average roughness of the prepared disks was examined by AFM topography scans and it was about $120 \mathrm{~nm}$. The drops of pure polymers were formed on the MMT disks at meltcompounding process temperature. Then, the samples were left in nitrogen atmosphere to reach the mechanical equilibrium. The equilibrium advancing and receding contact angles were measured by video recordings of the drops.

Table 2. Surface tension and viscoelastic properties of the samples used in the interfacial tension measurements at $155^{\circ} \mathrm{C}$

\begin{tabular}{|l|c|c|c|}
\hline \multicolumn{1}{|c|}{ Sample } & $\begin{array}{c}\text { Surface } \\
\text { tension } \\
{[\mathbf{m N} / \mathbf{m}]}\end{array}$ & $\begin{array}{c}\text { Zero shear } \\
\text { viscosity } \\
{[\mathbf{P a} \cdot \mathbf{s}]}\end{array}$ & $\begin{array}{c}\mathbf{G}^{\prime} \text { at } \boldsymbol{\omega}= \\
\mathbf{0 . 1} \mathbf{~ r a d} / \mathbf{s} \\
{[\mathbf{P a}]}\end{array}$ \\
\hline PE & $26.7 \pm 1.1$ & 113980 & 1900 \\
\hline EVA & $28.8 \pm 0.9$ & 60.4 & 0.185 \\
\hline PE100MMT3 & $31.8 \pm 0.2$ & 216540 & 1920 \\
\hline EVA100MMT3 & $32.8 \pm 0.9$ & 192770 & 0.508 \\
\hline
\end{tabular}

\section{Results and discussion}

\subsection{Microstructure}

\subsubsection{Biphasic morphology}

By considering the SEM micrographs of the prepared blends and the related nanocomposites (Figure 1a-1f), it can be assessed that pristine MMT has a noticeable effect on the biphasic morphology of PE/EVA blends. Regardless of the sample composition, the SEM micrographs obviously indicated that the presence of natural nanoclay did not vary the type of blend morphology. Despite this fact, the addition of the nanoparticles resulted in the formation of narrower fibrils, finer biphasic morphologies and reduced dispersed-domain size for all of the prepared blends except for PE70EVA30. It is noteworthy that the mentioned compatibilization effect of MMT was also deduced from the SEM micrographs of PE40EVA60 and PE30EVA70 blends which are not shown in Figure 1. In contrast to the observed compatibilization effect of nanoclay, the EVA domain size increased for PE70EVA30 blend distinctly by taking a closer look at Figure $1 \mathrm{a}$ and $1 \mathrm{~b}$. Quantitative analysis of the dispersed domain size for the samples with matrix-dispersed morphology (PE70EVA30 and PE30EVA70 blends plus the related nanocomposites) showed that the corresponding diameter $\left(D_{\mathrm{v}}\right)$ of EVA domains was raised from 9.26 to $26.27 \mu \mathrm{m}$, whereas $D_{\mathrm{v}}$ of PE dispersed-domains exhibited an inverse trend by the presence of nanoparticles and was reduced from 16.43 to $7.67 \mu \mathrm{m}$ for PE30EVA70 blend.

According to the results, the biphasic morphology transition from matrix-dispersed to co-continuous, by increasing the EVA content, caused an alteration in the influence of inorganic filler from demixing effect to a more conventional compatibilization effect. Further evidence on this phenomenon is the results of EVA co-continuity index measurements collected in Table 3. The mentioned examinations as a 3-dimensional analysis of biphasic morphology proved that the continuity of EVA-rich domains was enhanced or remained unchanged by adding the nanoparticles except for PE70EVA30 blend. The EVA co-continuity index was declined for the PErich blend contained nanofiller (PE70EVA30MMT3). The compatibilization impact of nanoparticles resulted in the domain size reduction and co-continuity index increment in the polymer mixtures have 


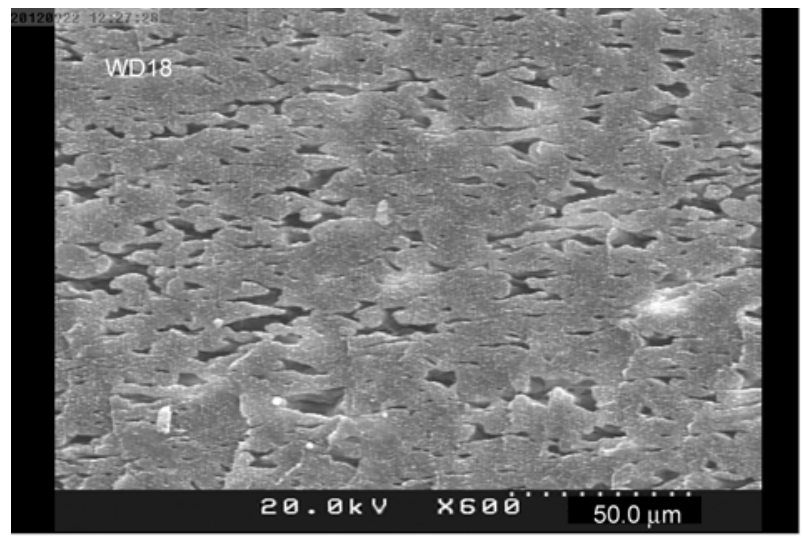

a)

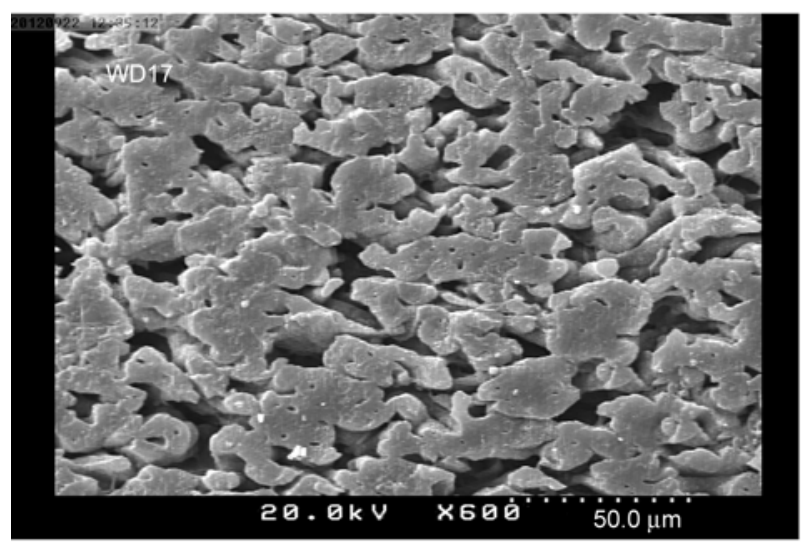

c)

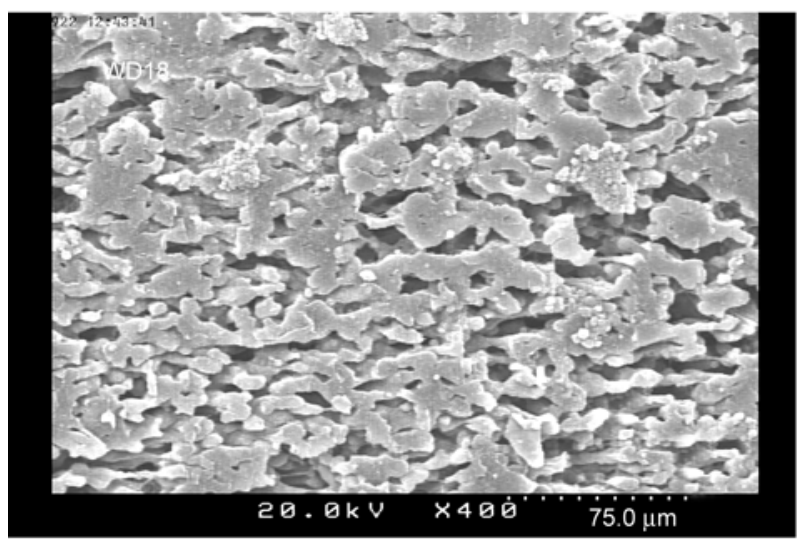

e)

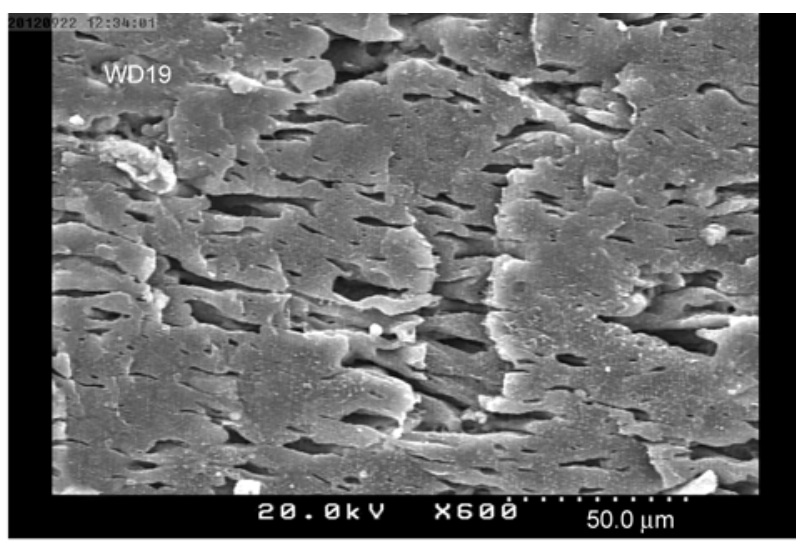

b)

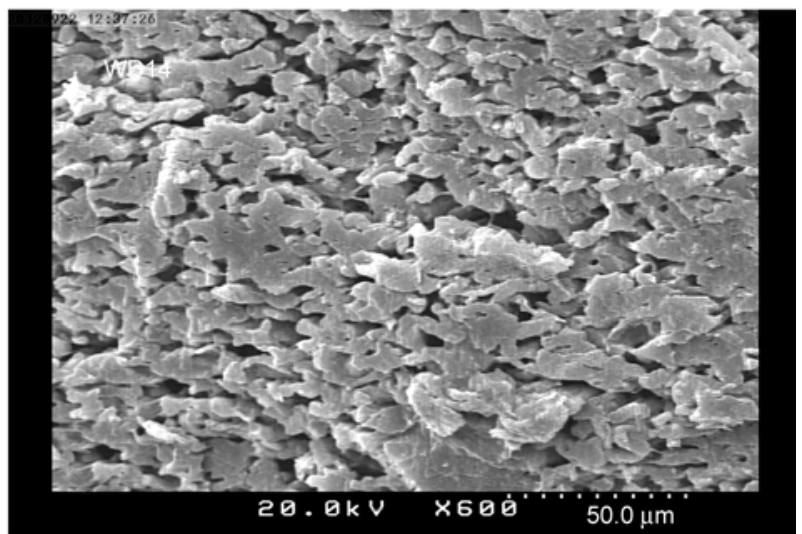

d)

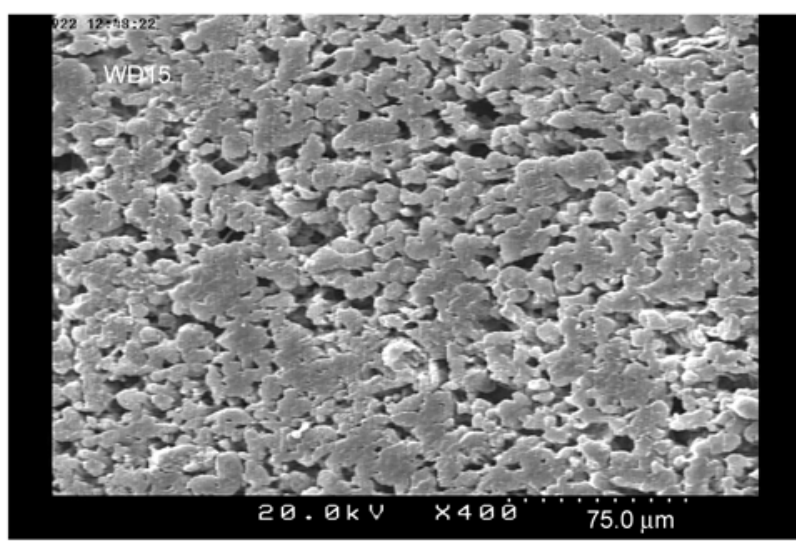

f)

Figure 1. SEM micrographs of (a) PE70EVA30, (b) PE70EVA30MMT3, (c) PE60EVA40, (d) PE60EVA40MMT3, (e) PE50EVA50, and (f) PE50EVA50MMT3

Table 3. Co-continuity index [\%] of EVA in the virgin blends and the related nanocomposites containing $3 \mathrm{wt} \% \mathrm{MMT}$

\begin{tabular}{|l|c|c|c|c|c|c|c|}
\hline \multicolumn{1}{|c|}{ Sample } & PE100 & PE70EVA30 & PE60EVA40 & PE50EVA50 & PE40EVA60 & PE30EVA70 & EVA100 \\
\hline Virgin blend & 0 & 73.8 & 83.0 & 90.8 & 97.9 & 5.53 & 0 \\
\hline Nanocomposite & 0 & 67.3 & 89.5 & 90.9 & 97.0 & 16.80 & 0 \\
\hline
\end{tabular}

been also reported by other groups [5-7, 27]. However, the observed contradiction between two different effects of pristine MMT on the biphasic morphology can be clarified by investigating the state of nanoparticle localization as well as dispersion.

\subsubsection{The states of MMT dispersion and localization}

To investigate these states, the AFM images and TEM micrographs of PE70EVA30MMT3, PE60EVA40 MMT3 and PE50EVA50MMT3 samples were pre- 


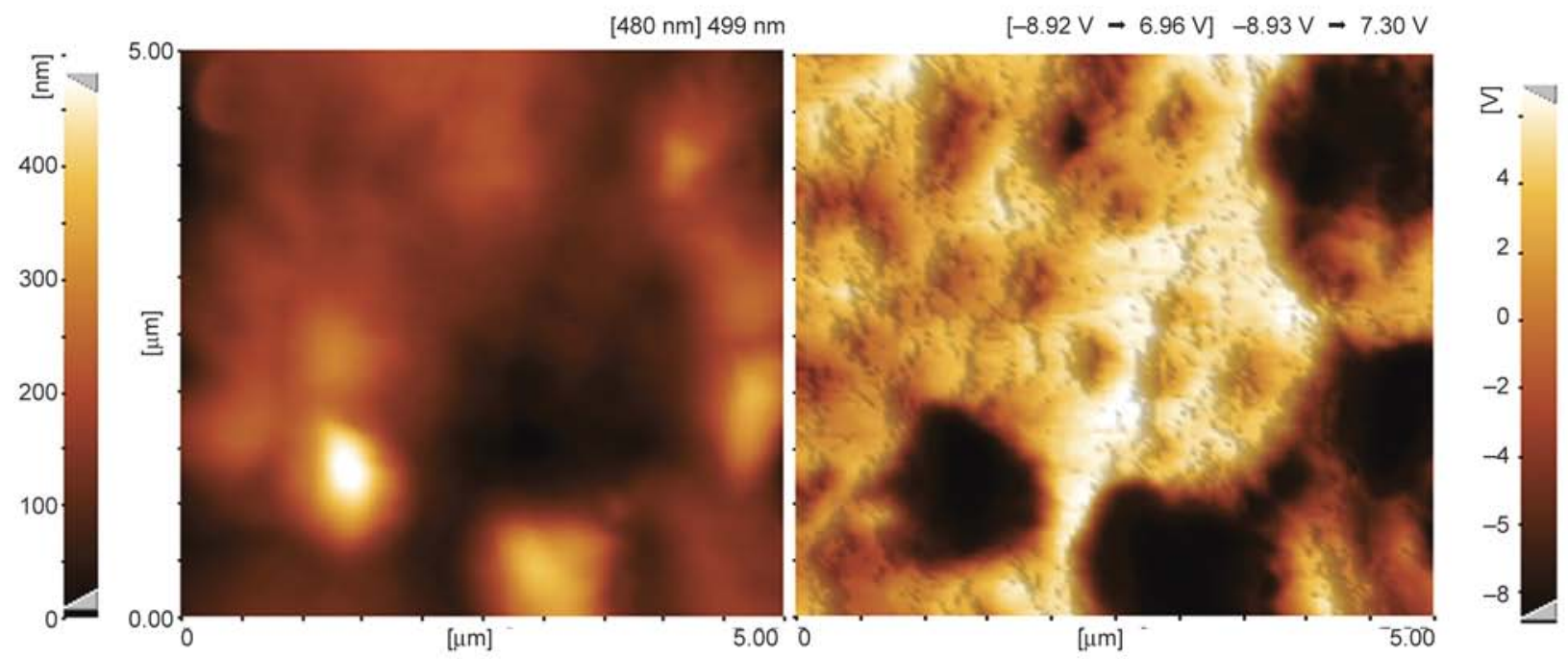

a)

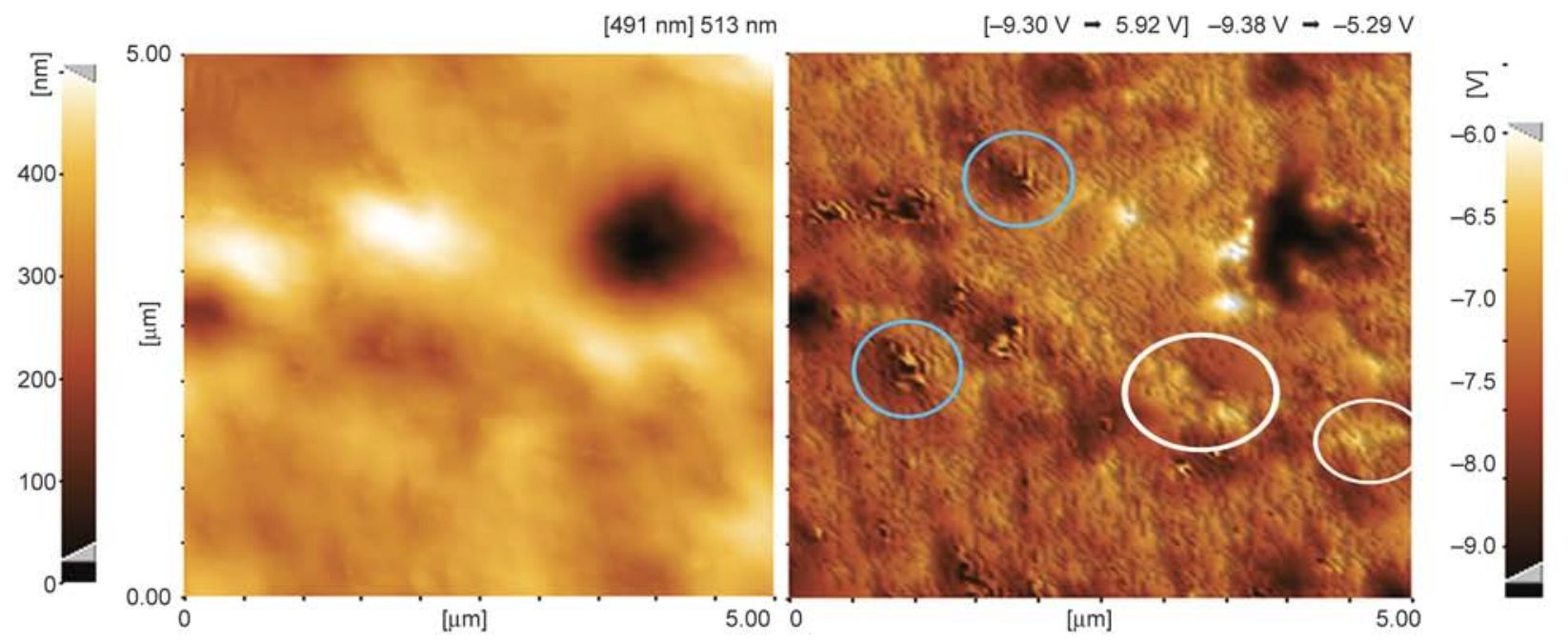

b)
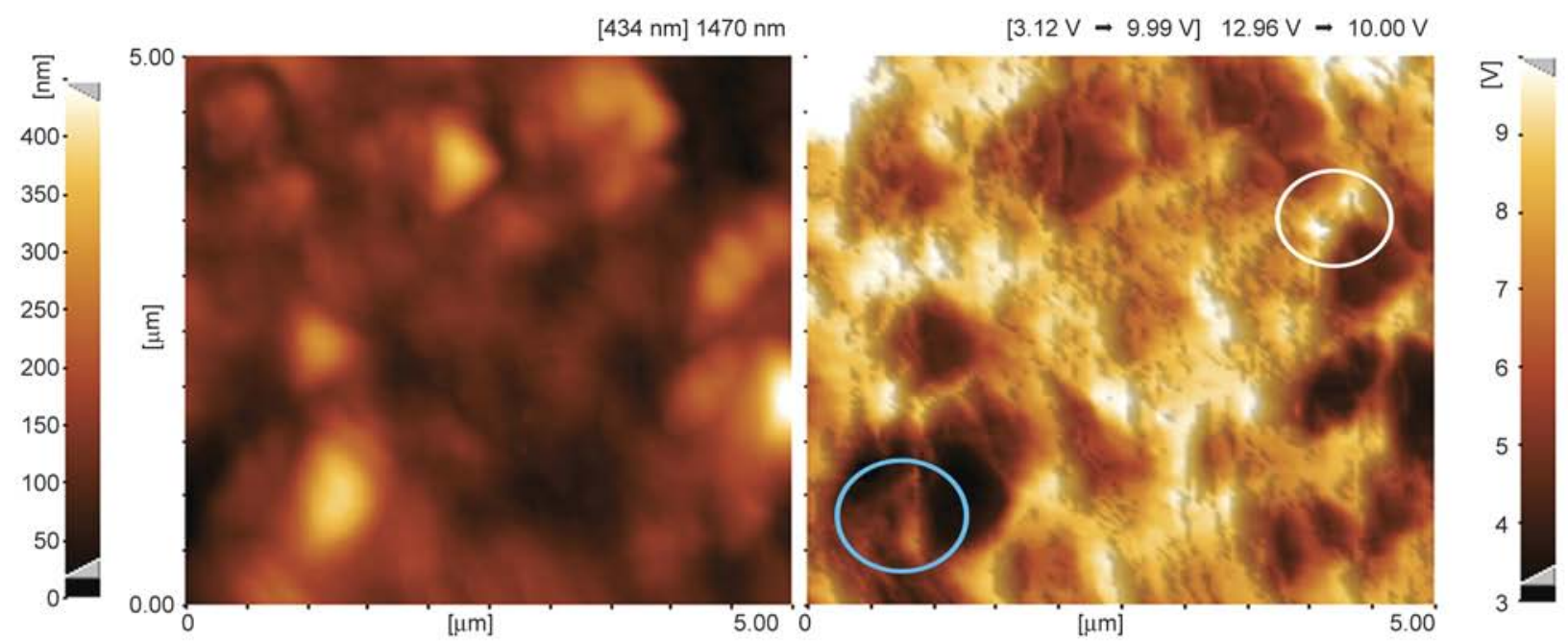

c)

Figure 2. AFM images of (a) PE70EVA30MMT3, (b) PE60EVA40MMT3, (c) PE50EVA50MMT3. Left and right images show height and phase-mode micrographs, respectively. Z-axes are on the right and left sides of images. Blue and white ellipses mark nanoclay stacks partitioned into EVA and PE domains, respectively. 


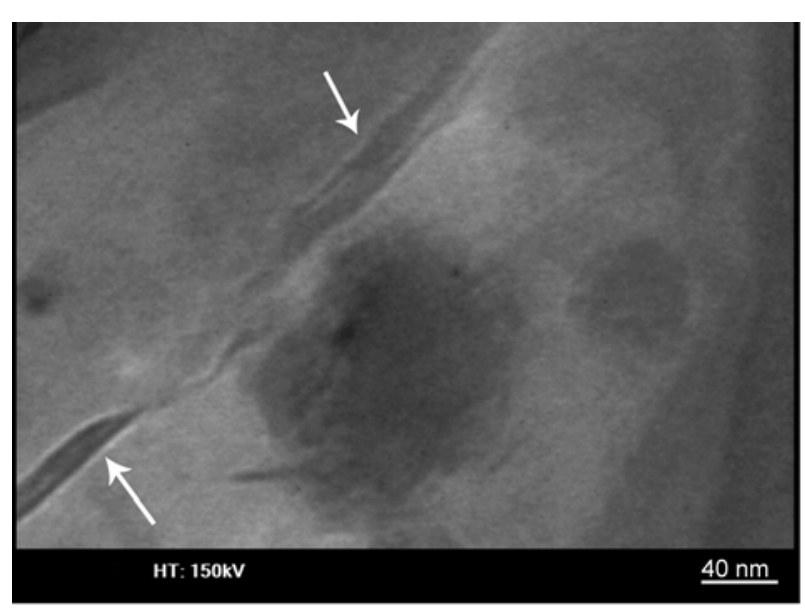

a)

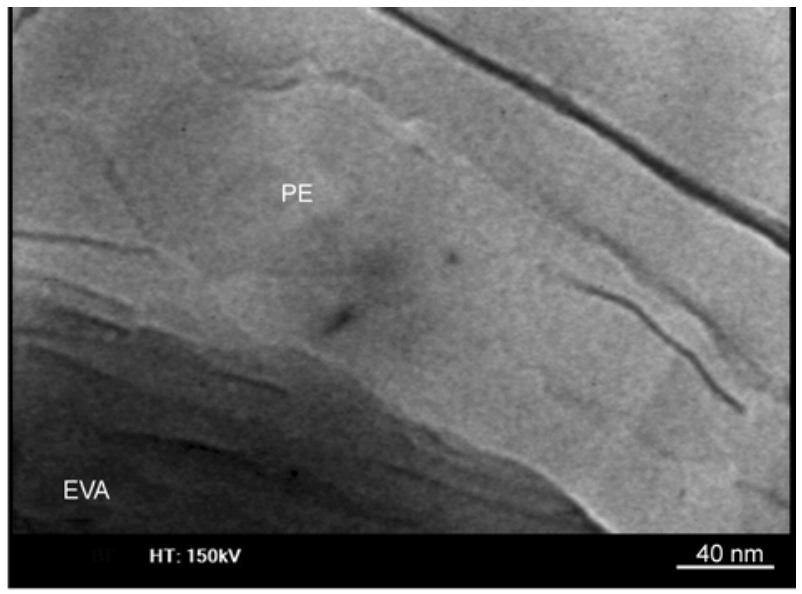

b)

Figure 3. TEM micrographs of (a) PE70EVA30MMT3 and (b) PE60EVA40MMT3. Intercalated MMT stacks were marked by arrows. EVA dispersed-domains can be discerned as darker areas.

pared and illustrated in Figure 2 and 3. The phase contrast images of the scanning force microscopy have been deduced to be sensitive to the sample surface properties such as modulus, viscoelastic characteristics and chemical composition [28]. Thus, different components of PE/EVA/MMT films having highly different stiffness and viscoelasticity were contrasted with each other sharply, especially in the phase-mode image of PE70EVA30MMT3 sample. As can be found in the phase contrast image of PE70EVA30MMT3 sample (Figure 2a), EVA domains were observed as black holes and brown features. Whereas PE phase could be recognized as yellow areas in the images. Likewise the other work [29], inorganic nano-layered stacks can be identified as white features in PE phase and light brown ones in EVA domains. A comparison of the phase contrast images of these nanocomposites showed that the nanoparticles were mainly confined to PE phase and the interface of two phases in PE70EVA30 MMT3 sample (see Figure 2a). While for the other nanocomposites, silicate nanolayers were localized in EVA domains as well. Blue and white ellipses in Figure $2 b$ and $2 c$ mark the nanoclay stacks partitioned into EVA and PE domains, respectively. Due to the larger amounts of nanoparticles localized in EVA domains and enhancements of EVA stiffness and viscoelasticity, the phase contrast of two phases were reduced for the nanocomposites containing more than $30 \mathrm{wt} \%$ of EVA. In a similar manner, TEM micrographs of these nanocomposites verify the observed states of MMT partitioning. As shown in Figure 3a, intercalated nanoclay stacks were localized in PE for PE70EVA30MMT3 nanocom- posite, which marked by white arrows and EVA darker domains were empty of MMT. Contrary to this nanocomposite, MMT stacks can also be found in EVA domains and at the interface of two phases in the other nanocomposite (see Figure 3b).

The nanoparticle preference for being thermodynamically localized in which domains was quantitatively evaluated by measuring the mechanical equilibrium contact angles and the interfacial tension between each polymer and nanoclay disks. The mentioned interfacial tensions were calculated using the Young equation with the assumption that the solid surface is perfectly smooth and rigid. The roughness measurements on the prepared clay disks showed that the solid surface was relatively flat (mean roughness $\left(R_{\mathrm{a}} \simeq 120 \mathrm{~nm}\right)$. The Young contact angles were determined using advancing and receding equilibrium angles following the work of Tadmor [30]. The results represented in Table 4 show that contrary to the EVA contact angle $\left(\theta_{\mathrm{c}}<90^{\circ}\right)$, the PE contact angle on pristine nanoclay is more than $90^{\circ}$ indicating low wettability and solid-liquid weak interaction. Higher wettability of the EVA melt led to the lower amount of interfacial tension. Therefore, the EVA melt at processing temperature could wet the nanoparticle surfaces better. In spite of this fact, the measured interfacial tensions are not

Table 4. Equilibrium Young contact angle $\left(\theta_{\mathrm{c}}\right)$ of polymer melts on nanoclay disks and corresponding interfacial tensions measured at $155^{\circ} \mathrm{C}$

\begin{tabular}{|l|c|c|}
\hline \multicolumn{1}{|c|}{ Polymer drop } & $\begin{array}{c}\boldsymbol{\theta}_{\mathbf{c}} \\
{\left[{ }^{\circ}\right]}\end{array}$ & $\begin{array}{c}\text { Interfacial tension } \\
{[\mathbf{m N} / \mathbf{m}]}\end{array}$ \\
\hline $\mathrm{PE}$ & $99.7 \pm 3$ & $296.5 \pm 2.2$ \\
\hline EVA & $19.1 \pm 1$ & $264.8 \pm 1.5$ \\
\hline
\end{tabular}


Table 5. XRD results of MMT and some of the prepared samples

\begin{tabular}{|l|c|c|c|c|c|c|}
\hline \multicolumn{1}{|c|}{ Sample } & MMT & PE100MMT3 & PE70EVA30MMT3 & PE50EVA50MMT3 & PE30EVA70MMT3 & EVA100MMT3 \\
\hline Peak, $2 \theta\left[^{\circ}\right]$ & 7.49 & $1.89 ; 7.1$ & $1.74 ; 7.04$ & $1.88 ; 6.85$ & $2.03 ; 7.49$ & $2 ; 7.49$ \\
\hline Related d-spacing $[\mathrm{nm}]$ & 1.18 & $4.66 ; 1.24$ & $5.07 ; 1.26$ & $4.7 ; 1.29$ & $4.35 ; 1.18$ & $4.41 ; 1.18$ \\
\hline
\end{tabular}

extremely different because of high surface energy of unmodified nanoclay.

Due to this high surface energy of natural nanoclay, silicate nanolayers fell through being dispersed during melt-compounding process and remained aggregated into micrometer-sized tactoids which can be observed even by the optical microscopy at higher magnifications (refer to part 3.3). Although the applied polymers and the inorganic unmodified nanofiller were expected to be thoroughly immiscible, intercalated morphology was achieved for the nanocomposites on the evidence of the following examinations. According to the modeling work of Ginzburg et al. [31], even in the immiscible part of the phase map for the clay-polymer system wherein the interaction between clay and polymer is too weak, the intercalated morphologies still could be obtained because of the equilibration of densities in polymer bulk and clay galleries. The Peak characteristics of XRD patterns for pristine MMT and the prepared nanocomposites are presented in Table 5. For the nanocomposites, two distinct peaks were discerned in XRD patterns which appeared at smaller angles, $2 \theta\left(\sim 2\right.$ and $\left.\sim 7^{\circ}\right)$, than the peak position of natural MMT ( $7.49^{\circ}$ and corresponding $\mathrm{d}$-spacing of $1.179 \mathrm{~nm}$ ) indicating an increment in the d-spacing of clay platelets.

Shifting the peaks of PE70EVA30MMT3 and PE50EVA50MMT3 compounds toward lower angles in comparison with the peak position of PE100MMT3 sample is worthy to be considered. During sample preparation process, low melting EVA phase (melting temperature $\left(T_{\mathrm{m}}=65.9^{\circ} \mathrm{C}\right)$ could coat the clay stacks and diffused into the clay interlayer spacing before melting of the PE phase $\left(T_{\mathrm{m}}=132.8^{\circ} \mathrm{C}\right)$. Because of EVA chain diffusion, clay d-spacing increased and the hydrophilic nature of nanoparticle surfaces was modified. Thus, it could facilitate the nanoclay intercalation by hydrophobic PE macromolecules. The existence of both polymer chains in the same gallery was also reported by other groups $[5,6]$. Obtaining the intercalated morphology in the nanocomposites can also be verified by microscopic observations. TEM micrographs shown in Figure 3 indicated the achievement of intercalated microstructure for the prepared hybrid systems.

\subsubsection{Effective parameters for morphology development}

Better understanding of the microstructure of nanocomposites could clarify the observed compositiondependent effect of nanoparticles on the biphasic morphology. In the melt blending process of two polymers $(A$ and $B)$, the deformation and breakup of domains relies on capillary number $(\mathrm{Ca})$ and viscosity ratio $(P)$ (Equations (2) and (3)):

$C a=\frac{\tau R}{\gamma_{\mathrm{AB}}}$

and

$P=\frac{\eta_{\mathrm{d}}}{\eta_{\mathrm{m}}}$

where $\tau, R$ and $\gamma_{\mathrm{AB}}$ are the applied stress of external flow, characteristic domain size and interfacial tension, respectively. In addition, $\eta_{\mathrm{m}}$ and $\eta_{\mathrm{d}}$ are the viscosity of the matrix and dispersed phases, respectively. When $C a$ exceeds a critical value ( $\left.C a_{\text {crit }}\right)$, the domain breakup occurs. $C a_{\text {crit }}$ depends on the viscosity ratio and reaches the minimum value at $P=1$ [32]. The presence of natural MMT in the used polymers and the resultant chain confinement in the clay galleries alters the viscosity and elasticity ratio. As can be seen in Table 2, the nanoparticles have significant influence on the viscoelastic properties of the EVA phase and increase the zero shear viscosity up to 3 orders of magnitude. Comparing with the EVA polymer, this effect is not very noticeable for the PE phase. The addition of $3 \mathrm{wt} \%$ of natural MMT to the PE polymer enhanced the zero shear viscosity to almost twice its value. As a result, for the obtained hybrid systems containing more than $30 \mathrm{wt} \%$ of EVA, in which the amount of nanoparticle localized in EVA domains is substantial, the viscosity and elasticity ratio of phases change and become closer to 1 . In other words, the localization of nanoclay in EVA phase reduces the viscoelastic asymmetry of phases in these systems, which is a direct result of more considerable effect 
of MMT on the EVA viscoelastic properties. Therefore, $C a_{\text {crit }}$ diminishes and breakup can take place at lower shear rates. Besides, Wu's empirical method (Equation (4)) [33] verified that the characteristics domain size is brought down as viscosity ratio approaches to 1:

$\frac{\tau \eta_{\mathrm{m}} R}{\gamma_{\mathrm{AB}}}=4(P)^{ \pm 0.84}$

where the positive exponent is for $P>1$ and the negative one for $P<1$. Hence, as the viscosity ratio approaches to 1 for the mentioned nanocomposites, $R$ reduces to lower values. In contrast to these nanocomposites, the EVA-dispersed compound wherein the majority of clay stacks were confined to the PE matrix has even a lower amount of viscosity ratio in comparison with the pure blend (PE70EVA30). As a result, $C a_{\text {crit }}$ and resultant droplet size are raised. This state of partitioning worsens the dynamic asymmetry of two components. However, the MMT localization in the PE phase for PE70EVA30MMT3 is not thermodynamically favorable and subsequent melt-blending process may shift it to the EVA dispersed domains.

Another influential factor in dictating the final morphology is the interfacial tension between the two polymers. The interfacial tension of the pure components and the pristine nanoclay modified constituents are gathered in Table 6 . By adding $3 \mathrm{wt} \%$ of nanofiller to each phase, the interfacial tension between the polymers was diminished to the lower values, especially for the systems wherein the PE phase contained natural MMT. The observed decline in $\gamma_{\mathrm{AB}}$ can explain the interfacial activity of unmodified filler stacks at the interface of the PE and EVA

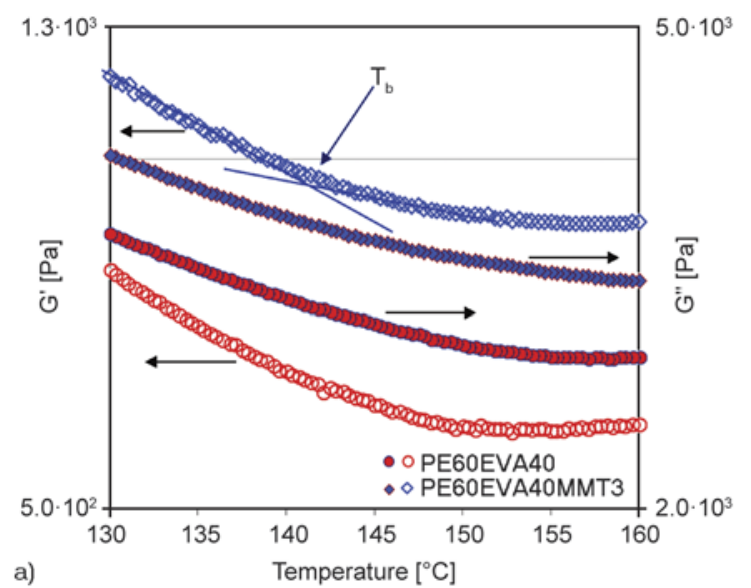

Table 6. Interfacial tension $\left(\gamma_{\mathrm{AB}}\right)$ between PE and EVA in the presence of natural MMT measured at $155^{\circ} \mathrm{C}$

\begin{tabular}{|l|l|l|c|}
\hline $\begin{array}{c}\text { Measurement } \\
\text { method }\end{array}$ & Fiber/Drop & \multicolumn{1}{|c|}{ Matrix } & $\begin{array}{c}\gamma_{\mathrm{AB}} \\
{[\mathbf{m N} / \mathbf{m}]}\end{array}$ \\
\hline $\begin{array}{l}\text { Imbedded fiber } \\
\text { retraction }\end{array}$ & PE & EVA & $1.79 \pm 0.47$ \\
\hline $\begin{array}{l}\text { Imbedded fiber } \\
\text { retraction }\end{array}$ & PE & EVA100MMT3 & $1.4 \pm 0.41$ \\
\hline $\begin{array}{l}\text { Imbedded fiber } \\
\text { retraction }\end{array}$ & PE100MMT3 & EVA & $0.97 \pm 0.30$ \\
\hline Sessile drop & EVA & PE & $2.16 \pm 0.63$ \\
\hline Sessile drop & EVA & PE100MMT3 & $1.07 \pm 0.25$ \\
\hline
\end{tabular}

phases, though this effect does not seem to be as significant as the interfacial activity of organically modified nanoclay evaluated in other blends [5-7]. However, the observed interfacial tension reduction can have an impact on the deformation and breakup of blend domains, which is not our priority to study it in this work. Nonetheless, the compatibilization influence of the pristine MMT causing a decrease in the value of $\gamma_{\mathrm{AB}}$ does not seem to dominate the development of biphasic morphology in comparison with the viscosity ratio factor for PE70EVA30 MMT3 nanocomposite.

\subsection{Phase separation diagram}

To investigate the phase separation of PE and EVA domains in the melt state before the crystallization temperature of $\mathrm{PE}$, two methods were used to determine the phase transition boundary: phase separation phenomenon recorded by the optical microscopy and the isochronal dynamic temperature sweeps. Figure 4 illustrates the dynamic temperature experiment of PE60EVA40 and PE60EVA40MMT3 samples during cooling ramp from well-mixed to the phase separated region. As can be observed in this

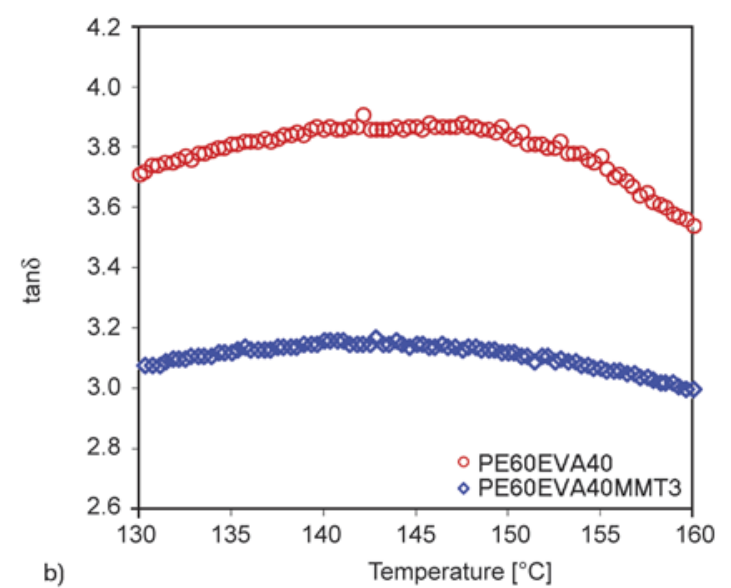

Figure 4. Isochronal dynamic temperature of (a) $G^{\prime}$ (hollow symbols) and loss modulus $\left(G^{\prime \prime}\right)$ (filled symbols) and (b) tan $\delta$ for PE60EVA40 and PE60EVA40MMT3 samples 
figure, a notable change in the slope of moduli is made as temperature approaches the phase transition boundary. Moreover, the addition of pristine nanoclay does not affect the viscoelastic behavior of the blend qualitatively. Only an increment in the magnitude of moduli and a reduction in the amount of loss tangent $(\tan \delta)$ can be seen. For the blends with weakly dynamic asymmetry due to small differences in the glass transition temperature of components such as the ones studied here, the contributions of concentration fluctuation and interface to the storage modulus $\left(G^{\prime}\right)$ are not substantial and just a deviation from the temperature dependence of $G^{\prime}$ in the mixed region can be observed [23]. Therefore, the temperature at which an increment in the slope of $G^{\prime}$ is detected and the corresponding peak position of $\tan \delta$ is employed to determine the onset temperature of phase separation. The demixing temperature of the prepared samples was also measured by optical microscopy. By cooling down the homogeneous melt, the threshold temperature below which phase separated domains were clearly seen was identified as binodal temperature $\left(T_{\mathrm{b}}\right)$. The phase separation diagrams of the prepared blends and nanocomposites obtained by the optical microscopy and rheology are displayed in Figure 5. The results demonstrated that $T_{\mathrm{b}}$ of the blends slightly decreased to the lower temperatures by adding pristine nanoclay except for PE70EVA30MMT3 sample. It seems that the presence of unmodified nanoparticles could diminish the composition dependency of phase transition temperature. According to the results of an analytical theory proposed by Ginzburg [13] which was developed to describe the impact of nanoparticles on the thermodynamics of binary polymer blends, at larger size of nanofillers, the entropy reduction of polymer chains due to the absorption on the solid surface becomes critical and it causes the homogeneous system to be destabilized. It is suggested that for these hybrid systems, the phase separation occurs between polymer-rich and nanoparticle-rich regions like conventional behavior of colloid-polymer mixtures. For the prepared nanocomposites that contained micrometersized agglomerated tactoids, the polymer-nanoparticle segregation could happen and worsen the system miscibility induced by nanoclay stacks. (It will be explained in the following section.). However, the mentioned segregation could intensify when the majority of nanoparticles localized in the more unfavorable phase domains (PE domains in PE70EVA30MMT3 sample). It has been confirmed both theoretically and experimentally that in the case wherein nanofiller prefers the minority component like PE70EVA30MMT3, the presence of nanoparticles reduces the system miscibility and phase separation temperature shifts to the lower values for LCST blends [11, 13, 23].

As mentioned before, the interfacial tension between each polymer component and unmodified nanoclay is remarkably higher than the interfacial tension of the used polymers (about 2 orders of magnitude). In spite of weak interaction of the used polymers with pristine nanoclay in comparison with the interaction

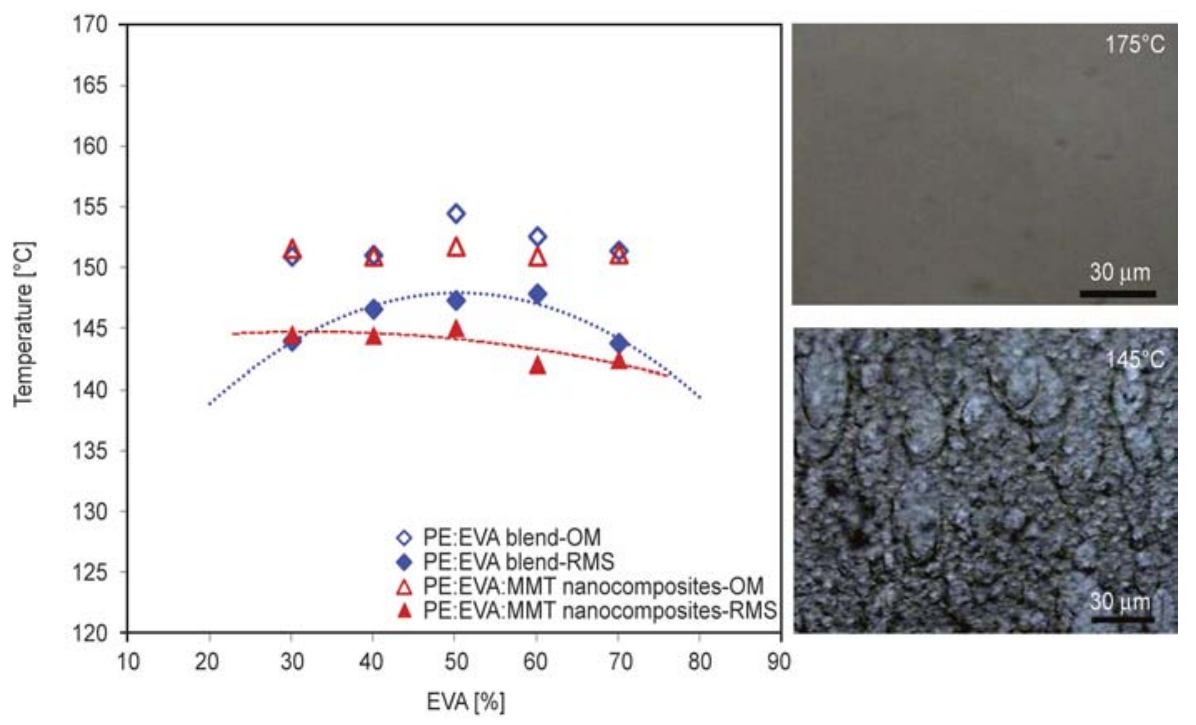

Figure 5. Phase diagram of PE:EVA blends and PE:EVA:MMT nanocomposites determined by means of rheology (RMS) and optical microscopy $(\mathrm{OM})$. Lines are drawn to guide eye. 
between two phases $\left(\gamma_{\mathrm{AF}}\right.$ and $\left.\gamma_{\mathrm{BF}}>>\gamma_{\mathrm{AB}}\right)$, the addition of nanoparticles was observed to improve the compatibility of the virgin blends a little. According to the theoretical work of He et al. [34], the intermixing of polymers can be promoted in the presence of nanofiller, even nanoparticles with relatively larger interaction parameters with polymer components than the interaction parameter of two polymers.

\subsection{Phase separation kinetics}

Nanofillers can influence the domain growth and phase separation kinetics of a binary blend by the pinning effect, which is considered as non-equilibrium compatibilization mechanism. The interaction of polymeric constituents with the solid surface diminishes macromolecular mobility, chain entropy and resultant phase separation rate in the system $[11,12,16]$. Seeking the track of phase transition kinetics, the complex viscosity $\left(\eta^{*}\right)$ of the prepared samples were measured at different temperatures across the phase diagram and are illustrated in Figure $6 \mathrm{a}$ and $6 \mathrm{~b}$ accompanied by the same results calculated via theoretical mixing rule. It can be clearly seen that $\eta^{*}$ of the virgin blends represents a definite positive deviation from theoretical results of mixing rule at higher temperatures wherein the melt is well-mixed. This result can be due to the cooperative motion or the collective relaxation of mixed polymer chains. Contrary to the positive deviation, $\eta^{*}$ of the obtained blends showed a negative deviation from the results of mixing rule as the temperature reduced and phase separation intensified apart from the PE-rich blend (PE70EVA30). The noticeable positive deviation of this blend at lower temperatures can be an outcome of the polymer chain interlocking at the interface. While the observed negative deviation of the others below the miscibility window is resulted from the formation of weak interface between two phases.

Although the pure mixtures showed a complicated positive-negative deviation for $\eta^{*}$ at temperatures far below the phase boundary, the complex viscosity of the obtained nanocomposites demonstrated a positive deviation for all compositions even at the lowest measured temperature, i.e. $130^{\circ} \mathrm{C}$. This behavior can be explained by two different actions of nanoclay stacks: firstly, providing in-situ grafts at the interface of phase-separated domains and reducing the interfacial tension; secondly, retarding the phase separation phenomenon due to the entropy reduction and diminished mobility of the polymer chains interacted with the inorganic solid surfaces. The latter action of nanoparticles inhibits the phase-separated domains to be thoroughly purified from the chains of other phase in the time-scale of experiment. To evaluate this effect, i.e. the non-equilibrium compatibilization impact of nanofiller, isothermal time sweep experiments were performed at equal depth in phase-separated region on the samples with 50:50 compositions and PE-rich ones (PE70EVA30 and PE70EVA30MMT3) displayed in Figure 6c. Clearly, for both samples, PE50EVA50 and PE50EVA50MMT3, the storage modulus continuously decreased with time after showing a maximum. The rate of this reduction was substantially affected by the addition of pristine MMT. Even though the virgin blend reached approximately the saturated stage, the magnitude of $G^{\prime}$ for PE50EVA50 MMT3 sample was continuing its gradual decline with time, even after passing $10000 \mathrm{~s}$, indicating much slower phase separation process in the presence of nanofiller. In the vicinity of nanoclay stacks, the macromolecular mobility reduces due to the restriction imposed by the intercalated morphology. As a result, the diffusion process of polymer chains is retarded causing a sharp decline in the amplitude of concentration fluctuation growth rate during phase separation phenomenon.

By considering the time sweep results of PE-rich samples (Figure 6c), it seems that nanoparticles in this blend play the same role as the one in PE50EVA50 blend and apply constraints on the concentration fluctuation process. In the time-scale of the measurements, the storage modulus of PE70EVA30 sample illustrates its continuous reduction with time, whereas for the corresponding nanocomposite, seemingly, $G^{\prime}$ has passed just the early stages of phase separation process. The slower phase transition phenomenon of this blend in the presence of pristine MMT can be verified by the optical microscopy images shown in Figure $6 \mathrm{~d}$ and 6 e. The observations indicate that the phase-separated domains, which can be discerned by optical microscopy, form over a longer period in the presence of nanoparticles and develop slower. The obtained results can confirm that even when the majority of nanoclay stacks is localized in one of the component domains, i.e. PE, nanoparticles can slow down the phase separation process. 

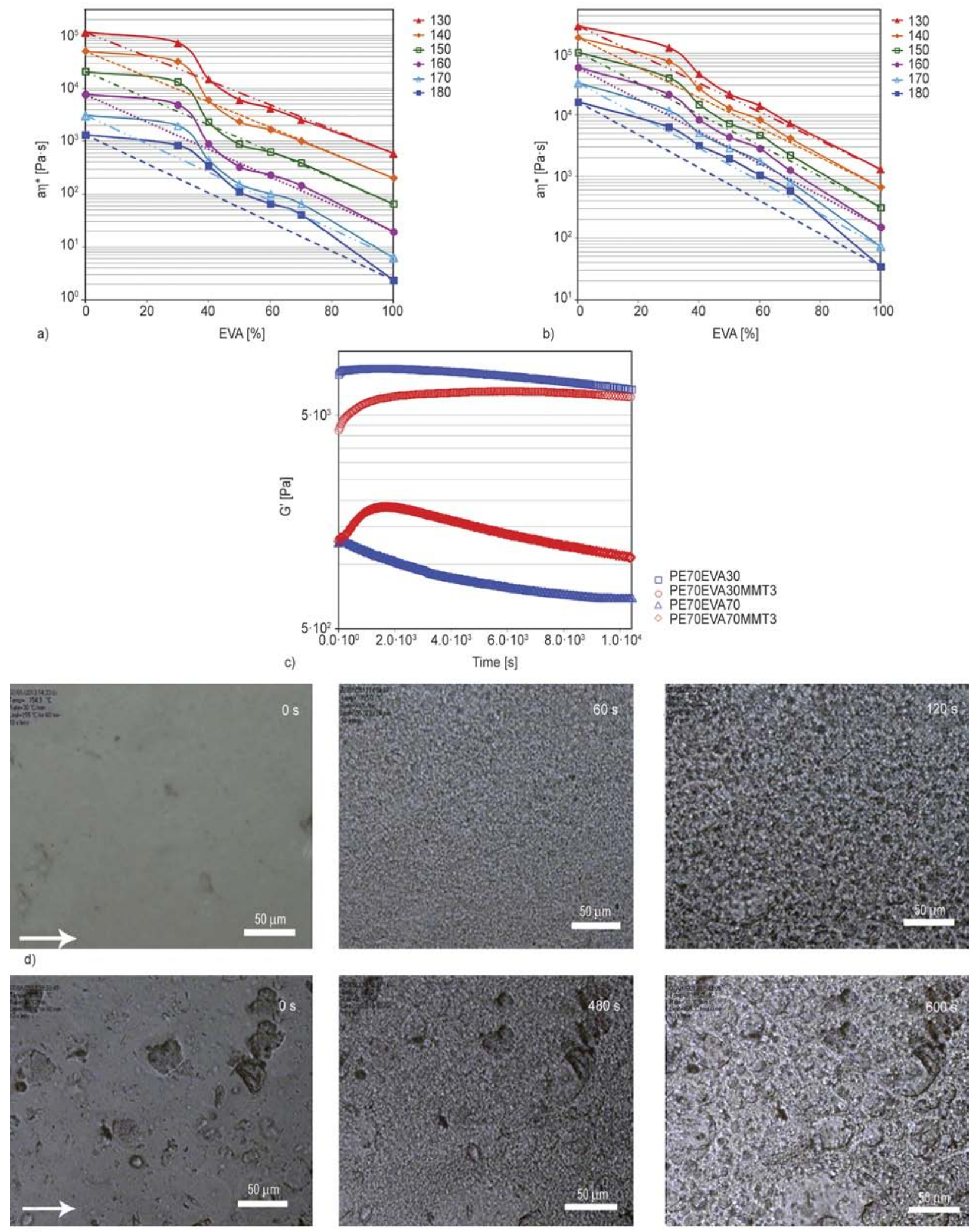

e)

Figure 6. (a) and (b) complex viscosity $\left(\eta^{*}\right)$ of virgin blends and nanocomposites, respectively, versus EVA composition obtained via experiments (points) and calculations using mixing rule (straight lines) at different temperatures across phase boundary. Curves are shifted along the vertical-axis. (c) time evolution of $G^{\prime}$ at frequency of $1 \mathrm{rad} / \mathrm{s}$ and with $1 \%$ strain; the experiment was performed at $T=155^{\circ} \mathrm{C}$ and $T=152^{\circ} \mathrm{CC}$ for PE50EVA50 and PE50EVA50MMT3, respectively, whereas it was carried out at $T=150^{\circ} \mathrm{C}$ for both PE70EVA30 and PE70EVA30MMT3. (d) and (e) the optical microscopy images of: PE70EVA30 and PE70EVA30MMT3, respectively, recorded during phase separation at $T=150^{\circ} \mathrm{C}$. 
The restrictions on macromolecular relaxation and phase separation phenomena imposed by natural MMT improved the compatibility between the used polymers and changed the immiscible PE/EVA blends to the partially miscible ones. As a direct result of the imposed limitations, the phase-separated domains cannot thoroughly purify themselves from the molecules of the other phase during any applied cooling process. This fact can be verified by further evidence obtained using dynamic-mechanical analysis.

The observed transition temperatures of the PE and EVA phases for different samples were collected in Table 7 . The $\beta$ transition peak due to the relaxation of the chain branches can be hardly detected for the PE phase. Moreover, $\alpha$ transition peak correlated with some types of motion existed in the crystalline regions was also absent for the EVA phase. The addition of nanoparticles increased the transition temperatures to the higher values for pure polymers indicating the interaction of polymer chains with the solid surface of MMT and limited macromolecular mobility. To investigate the miscibility of these two polymers in the amorphous zones, the $\gamma$ transition related to the glass transition temperature $\left(T_{\mathrm{g}}\right)$ for the obtained samples must be considered in more detail. For the virgin blends, the $\gamma$ transition peak of PE and EVA phases insignificantly varied in comparison with the $T_{\mathrm{g}}$ of pure components demonstrating the immiscibility of two phases, while the presence of nanoclay altered the $\gamma$ transition of polymeric constituents. Although the sample preparation method was the same, the glass transition temperatures of $\mathrm{PE}$ and EVA domains moved toward each other for PE70EVA30MMT3 and PE50EVA50MMT3 nanocomposites. Besides the observed miscibility enhancement, the addition of

Table 7. Different transition temperatures $\left[{ }^{\circ} \mathrm{C}\right]$ of $\mathrm{PE}$ and EVA phases in some of the obtained samples

\begin{tabular}{|l|c|c|c|c|}
\hline \multirow{2}{*}{\multicolumn{1}{c|}{ Sample }} & \multicolumn{2}{c|}{ PE phase } & \multicolumn{2}{c|}{ EVA phase } \\
\cline { 2 - 5 } & $\boldsymbol{\gamma}$ & $\boldsymbol{\alpha}$ & $\boldsymbol{\gamma}$ & $\boldsymbol{\beta}$ \\
\hline PE & -120.0 & 52.3 & - & - \\
\hline PE100MMT3 & -117.9 & 63.8 & - & - \\
\hline EVA & - & - & -147.6 & -20.0 \\
\hline EVA100MMT3 & - & - & -144.6 & -18.9 \\
\hline PE70EVA30 & -120.3 & 51.2 & -147.4 & -21.0 \\
\hline PE70EVA30MMT3 & -120.5 & 54.7 & -143.0 & -17.1 \\
\hline PE50EVA50 & -120.7 & 50.2 & -147.4 & -21.1 \\
\hline PE50EVA50MMT3 & -125.0 & 57.7 & -145.9 & -14.6 \\
\hline PE30EVA70 & -120.0 & - & -146.8 & -21.2 \\
\hline PE30EVA70MMT3 & -135.3 & - & -135.3 & -16.7 \\
\hline
\end{tabular}

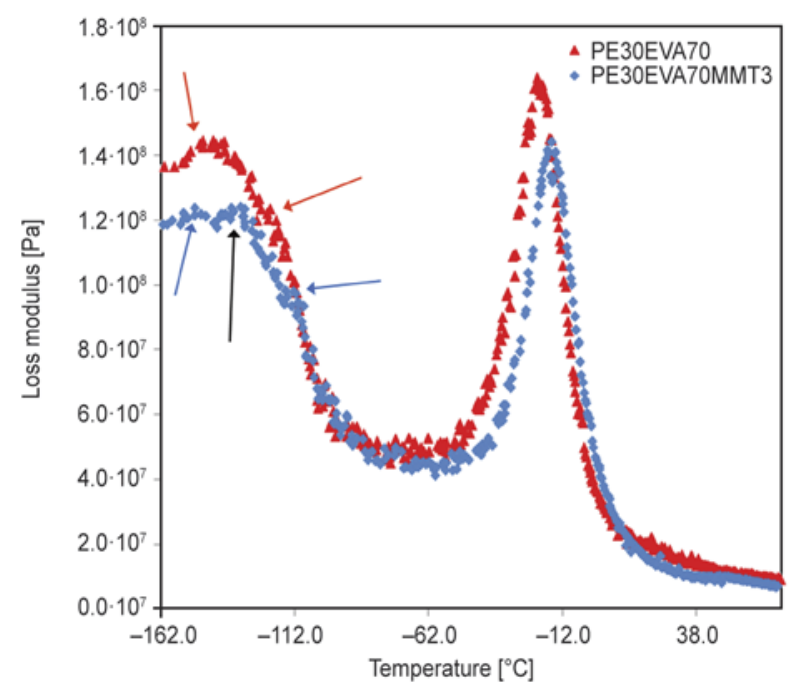

Figure 7. Loss modulus versus temperature for PE30EVA70 and PE30EVA70MMT3; the addition of MMT leads to appearance of an intermediate peak, which marks by a black arrow

nanoclay caused the appearance of a third peak, intermediate to that of the pure polymers for the EVA-rich nanocomposite (PE30EVA70MMT3). This intermediate peak marks by a black arrow in Figure 7, which show the DMA results of EVA-rich blend and the related nanocomposite. For the EVA domains in the nanocomposites, the presence of remained $P E$ chains after phase separation and the intercalated nanoclay affect the $T_{\mathrm{g}}$ of EVA component in the same way, whereas for the PE domains, the remained EVA molecules counteract the effects of MMT and reduce the $\gamma$ transition temperature of PE phase to lower values. However, the results can prove that the pristine MMT enhanced the miscibility of PE/EVA blends due to the pinning influence of nanoclay on the phase separation process.

\section{Conclusions}

The effects of pristine nanoclay, without any surface modification, on the biphasic morphology, phase transition diagram and phase separation kinetics of PE/EVA blends with UCST behavior were investigated.

- First of all, it was found that the compatibilization influence of natural MMT on the biphasic morphology of the virgin blends depends on the blend composition. While the addition of nanoparticles coarsens the matrix-dispersed morphology of the PE-rich blend, nanoclay plays the conventional role of compatibilizers as the morphology has become co-continuous. The observed 
contradiction was explained by the state of clay localization as evaluated by microscopic observations. Different states of clay partitioning alter the dynamic asymmetry of phases; while the localization in EVA phase reduces the viscoelastic asymmetry of phases in the blends having more than $30 \mathrm{wt} \%$ EVA, its substantial localization in PE phase worsens the dynamic asymmetry of two components and consequently, increases the EVA domain size.

- Interfacial tension measurements indicates that the intercalated nanoclay stack can reduce the interfacial tension between the used polymers in spite of the fact that the interfacial tensions between each polymer and unmodified nanoclay are about two orders of magnitude higher than the interfacial tension of pure polymers.

- The presence of micrometer-sized agglomerated tactoids of nanoclay slightly diminishes the binodal temperatures to lower values. Although it is theoretically observed that nanofiller with $\gamma_{\mathrm{AF}}$ and $\gamma_{\mathrm{BF}}>>\gamma_{\mathrm{AB}}$ can enforce the macromolecules to intermix better, the segregation of nanoparticle-rich and polymer-rich regions can diminish the compatibilization effect of pristine nanoclay.

- Regardless of the blend composition, the addition of unmodified nanoclay slows down the phase separation phenomenon and enhances the miscibility of PE/EVA mixtures in the amorphous regions by comparison with the virgin blends prepared via the same melt process.

\section{Acknowledgements}

The authors would like to thank Ms. Jalilzade (Mahar Fan Abzar Co.) for the preparation of AFM images and Dr. Saeb for his helpful discussion and assistance. Also, we thank Mrs. Ghasemirad for critical reading of the manuscript.

\section{References}

[1] Manas-Zloczower I.: Mixing and compounding of polymers: Theory and practice. Hanser, Munich (2009).

[2] Zhang Q., Yang H., Fu Q.: Kinetics-controlled compatibilization of immiscible polypropylene/polystyrene blends using nano- $\mathrm{SiO}_{2}$ particles. Polymer, 45, 19131922 (2004).

DOI: 10.1016/j.polymer.2004.01.037

[3] Si M., Araki T., Ade H., Kilcoyne A. L. D., Fisher R., Sokolov J. C., Rafailovich M. H.: Compatibilizing bulk polymer blends by using organoclays. Macromolecules, 39, 4793-4801 (2006).

DOI: $10.1021 / \mathrm{ma} 060125+$
[4] Behradfar A., Shojaei A., Sheikh N.: Rheological and mechanical characteristics of low density polyethylene/ethylene-vinyl acetate/organoclay nanocomposites. Polymer Engineering and Science, 50, 1315-1325 (2010).

DOI: $10.1002 /$ pen. 21660

[5] Ray S. S., Pouliot S., Bousmina M., Utracki L. A.: Role of organically modified layered silicate as an active interfacial modifier in immiscible polystyrene/ polypropylene blends. Polymer, 45, 8403-8413 (2004). DOI: $10.1016 /$ j.polymer.2004.10.009

[6] Dharaiya D. P., Jana S. C.: Nanoclay-induced morphology development in chaotic mixing of immiscible polymers. Journal of Polymer Science Part B: Polymer Physics, 43, 3638-3651 (2005). DOI: $10.1002 /$ polb.20657

[7] Hong J. S., Kim Y. K., Ahn K. H., Lee S. J., Kim C.: Interfacial tension reduction in $\mathrm{PBT} / \mathrm{PE} /$ clay nanocomposite. Rheologica Acta, 46, 469-478 (2007).

DOI: $10.1007 / \mathrm{s} 00397-006-0123-1$

[8] Elias L., Fenouillot F., Majesté J. C., Alcouffe P., Cassagnau P.: Immiscible polymer blends stabilized with nano-silica particles: Rheology and effective interfacial tension. Polymer, 49, 4378-4385 (2008).

DOI: $10.1016 /$ j.polymer.2008.07.018

[9] Pack S., Kashiwagi T., Cao C., Korach C. S., Lewin M., Rafailovich M. H.: Role of surface interactions in the synergizing polymer/clay flame retardant properties. Macromolecules, 43, 5338-5351 (2010). DOI: $10.1021 / \mathrm{ma100669g}$

[10] Wu D., Lin D., Zhang J., Zhou W., Zhang M., Zhang Y., Wang D., Lin B.: Selective localization of nanofillers: Effect on morphology and crystallization of PLA/PCL blends. Macromolecular Chemistry and Physics, 212, 613-626 (2011).

DOI: $10.1002 / \mathrm{macp} .201000579$

[11] Nesterov A. E., Lipatov Y. S.: Compatibilizing effect of a filler in binary polymer mixtures. Polymer, 40, 1347-1349 (1999). DOI: 10.1016/S0032-3861(98)00277-8

[12] Lipatov Y. S., Nesterov A. E., Ignatova T. D., Nesterov D. A.: Effect of polymer-filler surface interactions on the phase separation in polymer blends. Polymer, 43, 875-880 (2002). DOI: 10.1016/S0032-3861(01)00632-2

[13] Ginzburg V. V.: Influence of nanoparticles on miscibility of polymer blends. A simple theory. Macromolecules, 38, 2362-2367 (2005). DOI: $10.1021 / \mathrm{ma} 0482821$

[14] Balazs A. C., Ginzburg V. V., Qiu F., Peng G., Jasnow D.: Multi-scale model for binary mixtures containing nanoscopic particles. Journal of Physical Chemistry B, 104, 3411-3422 (2000).

DOI: $10.1021 / j p 993356+$ 
[15] Nesterov A. E., Lipatov Y. S., Horichko V. V., Gritsenko O. T.: Filler effects on the compatibility and phase separation kinetics of poly(vinyl acetate)-poly (methyl methacrylate) mixtures. Polymer, 33, 619-622 (1992). DOI: 10.1016/0032-3861(92)90740-N

[16] Yurekli K., Karim A., Amis E. J., Krishnamoorti R.: Influence of layered silicates on the phase-separated morphology of PS-PVME blends. Macromolecules, 36, 7256-7267 (2003).

DOI: $10.1021 / \mathrm{ma} 0207551$

[17] Zhang W., Lin M., Winesett A., Dhez O., Kilcoyne A. L., Ade H., Rubinstein M., Shafi K. V. P. M., Ulman A., Gersappe D., Tenne R., Rafailovich M., Sokolov J., Frisch H. L.: The use of functionalized nanoparticles as non-specific compatibilizers for polymer blends. Polymers for Advanced Technologies, 22, 65-71 (2011).

DOI: $10.1002 /$ pat.1875

[18] Yurekli K., Karim A., Amis E. J., Krishnamoorti R.: Phase behavior of PS-PVME nanocomposites. Macromolecules, 37, 507-515 (2004).

DOI: $10.1021 / \mathrm{ma} 0302098$

[19] Huang Y., Jiang S., Li G., Chen D.: Effect of fillers on the phase stability of binary polymer blends: A dynamic shear rheology study. Acta Materialia, 53, 5117-5124 (2005).

DOI: $10.1016 /$ j.actamat.2005.07.021

[20] El-Mabrouk K., Bousmina M.: Phase separation of polystyrene/poly(vinylmethylether)/organoclay nanocomposites. Journal of Nanoscience and Nanotechnology, 6, 472-482 (2006).

DOI: $10.1166 /$ jnn.2006.093

[21] El-Mabrouk K., Vandreuil S., Zeghloul A., Bousmina M.: Effect of shear on phase-separation in polystyrene/ poly(vinyl methyl ether)/organoclay nanocomposites. Journal of Nanoscience and Nanotechnology, 8, 18951900 (2008).

DOI: $10.1166 /$ jnn.2008.0191895

[22] Gharachorlou A., Goharpey F.: Rheologically determined phase behavior of LCST blends in the presence of spherical nanoparticles. Macromolecules, 41, 32763283 (2008).

DOI: $10.1021 / \mathrm{ma} 7020985$

[23] Gao J., Huang C., Wang N., Yu W., Zhou C.: Phase separation of poly (methyl methacrylate)/poly (styreneco-acrylonitrile) blends in the presence of silica nanoparticles. Polymer, 53, 1772-1782 (2012).

DOI: $10.1016 /$ j.polymer.2012.02.027
[24] Carriere C. J., Cohen A., Arends C. B.: Estimation of interfacial tension using shape evolution of short fibers. Journal of Rheology, 33, 681-689 (1989).

DOI: $10.1122 / 1.550033$

[25] Cohen A., Carriere C. J.: Analysis of a retraction mechanism for imbedded polymeric fibers. Rheologica Acta, 28, 223-232 (1989).

DOI: $10.1007 / \mathrm{BF} 01332854$

[26] Yasuda K.: Investigation of the analogies between viscometric and linear viscoelastic properties of polystyrene fluids. PhD Thesis, Massachusetts Institute of Technology (1979).

[27] Steinmann S., Gronski W., Friedrich C.: Influence of selective filling on rheological properties and phase inversion of two-phase polymer blends. Polymer, 43, 4467-4477 (2002). DOI: $10.1016 / \mathrm{S} 0032-3861(02) 00271-9$

[28] Raghavan D., Gu X., Nguyen T., VanLandingham M., Karim A.: Mapping polymer heterogeneity using atomic force microscopy phase imaging and nanoscale indentation. Macromolecules, 33, 2573-2583 (2002). DOI: $10.1021 / \mathrm{ma} 991206 \mathrm{r}$

[29] Hemati F., Garmabi H.: Compatibilised LDPE/LLDPE/ nanoclay nanocomposites: I. Structural, mechanical, and thermal properties. The Canadian Journal of Chemical Engineering, 89, 187-196 (2011).

DOI: $10.1002 /$ cjce. 20377

[30] Tadmor R.: Line energy and the relation between advancing, receding, and young contact angles. Langmuir, 20, 7659-7664 (2004).

DOI: $10.1021 / \mathrm{la} 049410 \mathrm{~h}$

[31] Ginzburg V. V., Weinhold J. D., Jog P. K., Srivastava R.: Thermodynamics of polymer-clay nanocomposites revisited: Compressible self-consistent field theory modeling of melt-intercalated organoclays. Macromolecules, 42, 9089-9095 (2009).

DOI: $10.1021 / \mathrm{ma} 9017263$

[32] Puyvelde P. V., Velankar S., Moldenaers P.: Rheology and morphology of compatibilized polymer blends. Current Opinion in Colloid and Interface Science, 6 , 457-463 (2001).

DOI: $10.1016 / \mathrm{S} 1359-0294(01) 00113-3$

[33] Wu S.: Formation of dispersed phase in incompatible polymer blends: Interfacial and rheological effects. Polymer Engineering and Science, 27, 335-343 (1987). DOI: 10.1002/pen.760270506

[34] He G., Ginzburg V. V., Balazs A. C.: Determining the phase behavior of nanoparticle-filled binary blends. Journal of Polymer Science Part B: Polymer Physics, 44, 2389-2403 (2006). DOI: $10.1002 /$ polb.20887 